\title{
Topographical Irregularity and Keratoconic Findings in Five Siblings and their Parents
}

\author{
1José M González-Méijome, ${ }^{2}$ Sofia C Peixoto-de-Matos, ${ }^{3}$ Anabela Soares, ${ }^{4}$ António Queirós \\ ${ }^{5}$ Alberto Díaz-Rey, ${ }^{6}$ José Salgado-Borges
}

\section{ABSTRACT}

Purpose: To report the clinical features of five siblings, four of them with positive diagnostic of keratoconus in different degrees of severity as well as their parents findings.

Materials and methods: Seven elements of the same family, five young siblings (2 males, 3 females), and their parents were screened for potential keratoconic signs. Topographic data from 60 normal eyes are also reported for comparison purposes. Complete ophthalmologic examination including biomicroscopic, topographic and refractive examination. Main outcome measures included biomicroscopic findings, refractive error and visual acuity, simulated keratometry, corneal eccentricity, indices of asymmetry and regularity.

Results: The more advanced case was present in the left eye of a male member, needing a rigid gas permeable lens to correct irregular astigmatism. Another brother also presented bilateral mild to moderate keratoconus with no apparent vision complaints. The third case diagnosed was one sister with history of monthly disposable soft toric lens to compensate a presumed initially regular astigmatism two years before. The remaining two cases being the older sister and one of the younger sisters presented the less noticeable signs, with confirmation of the pathology only in one of them and warranting a close followup of both due to the asymmetric corneal topography between both eyes as well as between the flatter superior and steeper inferior corneal areas.

Conclusion: This is the first reported case series involving diagnosis of keratoconus or atypical corneal topographies in several young siblings and their parents. Further evaluation of this and other cases with similar presentations might help to gain a deeper understanding on the potential genetic paths of keratoconus.

\footnotetext{
${ }^{1}$ Associate Professor, ${ }^{2}$ Research Fellow, ${ }^{3}$ Clinical Assistant

${ }^{4,5}$ Auxiliar Professor, ${ }^{6}$ Professor

1,4,5Department of Physics, CEORLab-Center of Physics University of Minho, Portugal

${ }^{2}$ Department of Contact Lenses and Pediatrics, CEORLabCenter of Physics, University of Minho, Portugal

${ }^{3}$ Department of Optometry, Private Practice, Portugal

${ }^{6}$ Department of Ophthalmology, Clinica Salgado Borges Portugal
}

Corresponding Author: José M González-Méijome Associate Professor, Department of Physics, CEORLab- Center of Physics, University of Minho, Portugal, Phone: +351253604072, e-mail: jgmeijome@fisica.uminho.pt
Keywords: Keratoconus, Family, Genetics, Corneal topography.

How to cite this article: González-Méijome JM, Peixoto-deMatos SC, Soares A, Queirós A, Díaz-Rey A, Salgado-Borges J. Topographical Irregularity and Keratoconic Findings in Five Siblings and their Parents. Int J Kerat Ect Cor Dis 2014;3(3): 130-135.

\section{Source of support: Nil \\ Conflict of interest: None}

\section{INTRODUCTION}

Keratoconus is a progressive, asymmetric, dystrophy of the cornea characterized by steepening and distortion of the cornea, apical thinning, and central scarring. It is generally bilateral and progressing asymmetrically between fellow eyes. More complete descriptions of the condition, its signs and symptoms are available in the strong body of literature surrounding this topic. ${ }^{1,2}$

Keratoconus is usually treated with contact lenses before other surgical procedures could be considered in case of lens intolerance or poor vision. ${ }^{3,4}$ Contact lenses most frequently used to compensate irregular astigmatism are currently made of rigid gas permeable materials either in conventional spherical, aspheric designs as well as other nonconventional designs. ${ }^{5,6}$ Despite these materials have shown to afford the best visual performance, ${ }^{7}$ sometimes physical intolerance or physical trauma to the corneal epithelium suggests that other approaches could be considered, using a diversity of materials, designs and fitting approaches. ${ }^{8,9}$

Family history is present in a remarkable percentage of patients, with different large scale reports showing numbers from $13.5 \%{ }^{10}$ reported in the USA for the Collaborative Longitudinal Evaluation of Keratoconus (CLEK) Study to $23.5 \%$ reported in New Zealand in a much smaller cohort of patients. Regarding the genetic etiology of keratoconus, even thought to be present, ${ }^{11}$ is not fully understood. Some authors assume that the disease follows an autosomal dominant pattern of transmission in certain types of keratoconus, ${ }^{12}$ and some candidate genes have already been identified. ${ }^{13,14}$ Reports on the presentation of keratoconus in different members of same family have been addressed in the literature. ${ }^{15,16}$ 
In the present case series, we present a series of four siblings ( 2 males and 3 females) presenting keratoconus in clinical stage or showing preclinical signs of the disease, such as asymmetry between fellow eyes, irregular astigmatism and typical and similar topographic patterns among all of them.

\section{MATERIALS AND METHODS}

Keratoconus suspect was raised when the first patients complained of worsening vision despite their young age, reported a history of frequent refractive changes or retinoscopy reflex was distorted. Full ophthalmological examination was conducted in the seven members of the family at different times. Nondilated subjective refractive error after retinoscopy (when possible to be reliably obtained) is reported in order to know the refractive error and visual skills under the patient's normal sighting condition. Topographic examination was conducted using a Medmont E300 corneal topographer (Medmont Pty, Melbourne, Australia). Topography maps were obtained after lens removal for at least 1 week in those patients wearing contact lenses at the time of examination. Along with the topographical patterns in the tangential curvature and using the absolute scale to make maps more easy to be compared across patients, other topographical indices were registered including simulated keratometry, eccentricity along the two principal meridians considering peripheral reference points at $4.5 \mathrm{~mm}$ to both sides of the visual corneal center and topographical surface asymmetry index (SAI), inferiorsuperior index (I-S) and surface regularity index (SRI).

All patients were also subjected to an exhaustive biomicroscopic examination. The presence of any of several signs of keratoconus such as engrossed corneal nerves beyond the peripheral corneal area, Fleischer ring with white and/or cobalt-blue filter, striae without or with contact lens in place, or signs of subepithelial corneal scars (Fig. 1) were required before diagnosis was confirmed. According with the results of the examination, each eye was graded according to the Keratoconus Severity Score ${ }^{17}$ into the following grades (grade 1: atypical topography; grade II: suspect topography; grade III: mild disease; grade IV: moderate disease; grade V: severe disease).

\section{RESULTS}

A 24-year-old male (brother \#1) was referred to our clinic in March 2007 with complaints of poor vision at night, more noticeable in his left eye. His eye care practitioner suspected of corneal ectasia due to difficulties in performing objective and subjective refraction in the patient's LE. Symptoms of poor vision were noted to worsen during the last year, particularly at night when the patient use to drive a truck. History was unremarkable regarding personal and family issues except one sister wearing soft contact lenses; did not describe history of atopy or allergies and reported he noticed the first signs of worsening vision in LE's vision about 2 years ago. The patient describes eye rubbing due to frequent burning sensation in his eyes. Uncorrected visual acuity (UCVA) was 20/30 in the RE and 20/200 in the LE. Refractive examination showed characteristic 'scissors reflex' in retinoscopy in both eyes, being impossible to obtain an endpoint in the LE. Subjective refraction was (RE $-0.50 \times 6020 / 20^{+}$and LE $-2.00 \times 12520 / 40$ ). Topography showed typical pattern of bilateral inferonasal steepening, more accentuated in the LE (Fig. 2-subject 1). Other topographic and biomicroscopic features are presented in Table 1.

One year later in June 2008, sister \#2, being 26 years old attended the clinic reporting slightly decreased visual acuity in her RE. The patient had a history of monthly disposable soft toric lens wear for the last two years until recently when she stopped wearing the lenses for the last two months until next eye care appointment because she was aware of worsening her vision in RE. Subjective refraction was RE-1.00 -0.75 × 70 20/25 $5^{-}$and LE $-0.50 \times$ 135 20/20). Keratometric data were unremarkable in LE but slightly steepened in RE compared with LE (Fig. 2subject 2). Topographic indices were significantly augmented in both eyes when compared with those obtained with the same instrument on a nonkeratoconic population of young adults, shown here in Table 1 for comparison term. Topographic pattern showed a slight steeper inferior area, particularly noticeable RE.

Sister \#3, came also at the same time accompanying her. In the end of the examination we advised her to be screened considering the results obtained in previous brother and sister. Initially reluctant because of her good vision, she accepted after explaining her known evidences of potential familial association. UCVA was 20/20 in both eyes and no signs of keratoconus were observed. Quantitative topographic analysis was normal for all indices and values, but again, a slight inferiorly displaced corneal apex was noted (Fig. 2-subject 3), maintained after several successive captures to ensure good alignment with the instrument's visual axis. UCVA was $20 / 20$ and subjective refraction was plano in both eyes. At that time it was also advised that the remaining two siblings that were in the country (one could not be screened) and parents should also be screened for the disease or potential topographical irregularities.

By February 2009, the sister \#4, being 28 years old came for screening. She reported to have good vision, with no apparent complains during night vision, decreased contrast, eye burning or other vision-related symptoms. At 

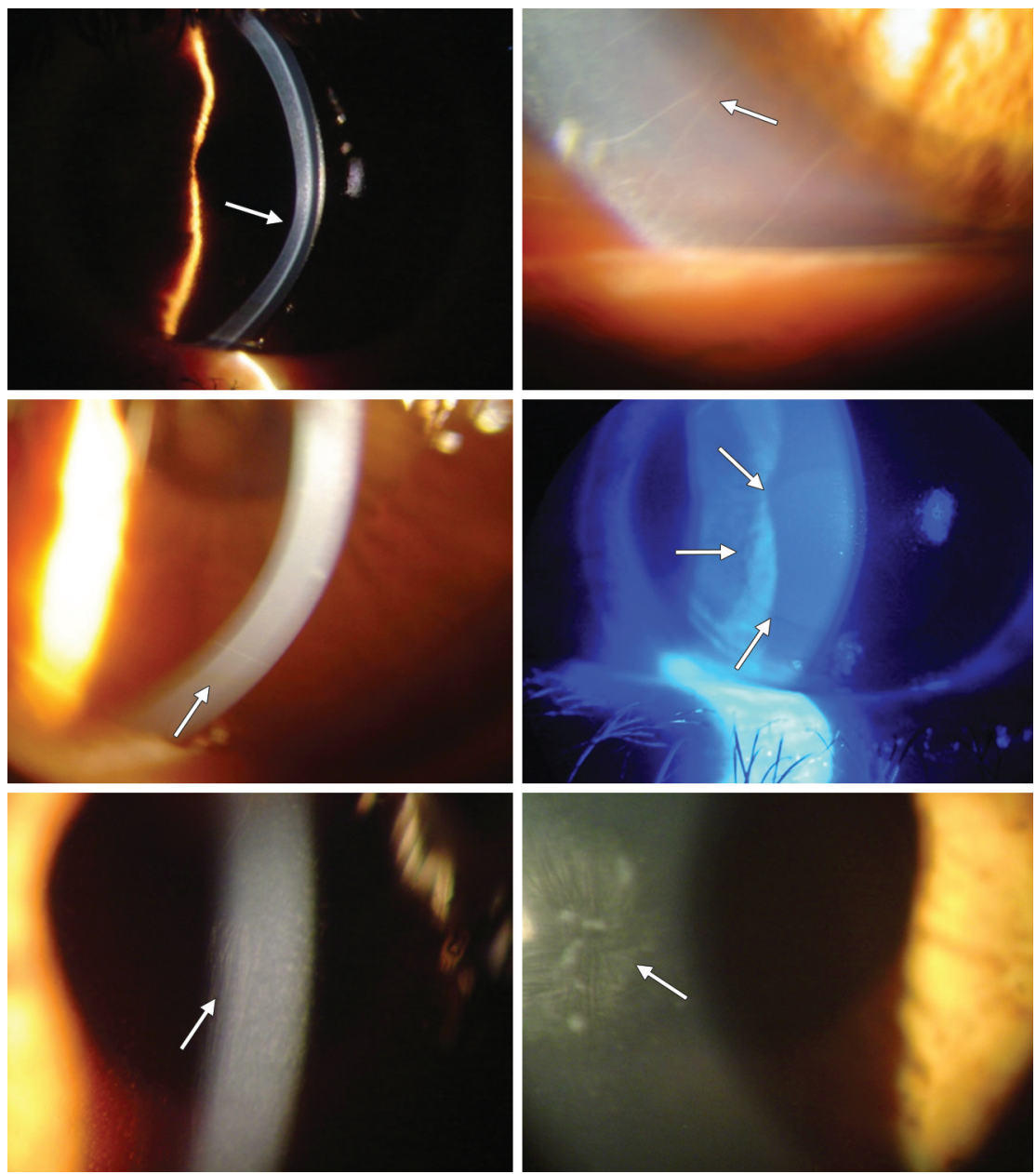

Fig. 1: Biomicroscopic features used to confirm diagnosis suspect, left to right, top to bottom (noncentral thinner point appearance, enlarged corneal nerves beyond limbal area, Fleischer ring either with white light, or with cobalt-blue filter, striae and subepithelial scars not related with superficial punctuate keratitis or contact lens abrasion)

Table 1: Right and left eye biomicroscopy and topographic details of patients. Top row shows data for a healthy young control population of 60 eyes previously surveyed at our lab using the same instrument

\begin{tabular}{|c|c|c|c|c|c|c|c|c|c|c|c|c|c|c|c|}
\hline & $K S S^{*}$ & Age & Nerves & $\begin{array}{l}\text { Fleischer's } \\
\text { ring }\end{array}$ & Striae & Scar & Flat $K$ & $\begin{array}{l}\text { Steep } \\
K\end{array}$ & Astig. & $\begin{array}{l}\text { Flat } \\
\text { E }\end{array}$ & $\begin{array}{l}\text { Steep } \\
E\end{array}$ & $B F S$ & $I-S$ & $S A I$ & SRI \\
\hline $\begin{array}{l}\text { Non- } \\
\text { keratoconic }\end{array}$ & & $\begin{array}{l}22.1 \\
\pm 2.3 \\
\end{array}$ & No & No & No & No & $\begin{array}{l}42.83 \\
\pm 2.3 \\
\end{array}$ & $\begin{array}{l}43.83 \\
\pm 2.3 \\
\end{array}$ & $\begin{array}{l}-1.00 \\
\pm 2.3 \\
\end{array}$ & $\begin{array}{l}0.68 \\
\pm 2.3 \\
\end{array}$ & $\begin{array}{l}0.41 \\
\pm 2.3 \\
\end{array}$ & $\begin{array}{l}7.94 \\
\pm 2.3 \\
\end{array}$ & $\begin{array}{l}-0.19 \\
\pm 2.3 \\
\end{array}$ & $\begin{array}{l}0.76 \\
\pm 2.3 \\
\end{array}$ & $\begin{array}{l}0.5 \\
\pm 2.3 \\
\end{array}$ \\
\hline \multicolumn{16}{|l|}{$\begin{array}{l}\text { Keratoconic } \\
\text { Patients }\end{array}$} \\
\hline Brother \#1 & II & 33 & Yes & No & No & No & 43.3 & 44.7 & -1.40 & 0.72 & 0.57 & 7.55 & 1.4 & 2.58 & 0.74 \\
\hline Brother \#1 & IV & 33 & Yes & Yes & Yes & No & 43.8 & 47.2 & -3.40 & 0.82 & 0.6 & 7.10 & 2.4 & 4.52 & 0.9 \\
\hline Sister \#2 & II & 26 & Yes & Yes & No & No & 42.8 & 46.4 & -3.60 & 0.73 & 0.91 & 7.78 & 1.02 & 1.97 & 0.82 \\
\hline Sister \#2 & II & 26 & Yes & No & No & No & 42.9 & 44.5 & -1.60 & 0.6 & 0.69 & 7.86 & 1.03 & 1.6 & 0.52 \\
\hline Sister \#3 & I & 26 & No & No & No & No & 42.7 & 43.5 & -0.80 & 0.56 & 0.28 & 7.92 & 0.48 & 0.58 & 0.35 \\
\hline Sister \#3 & I & 26 & No & No & No & No & 42.8 & 43.7 & -0.90 & 0.51 & 0.22 & 7.90 & 0.34 & 0.62 & 0.44 \\
\hline Sister \#4 & II & 28 & Yes & Yes & No & No & 43.3 & 43.9 & -0.60 & 0.52 & 0.08 & 7.81 & 0.54 & 0.69 & 0.5 \\
\hline Sister \#4 & II & 28 & Yes & No & No & No & 43.6 & 44.5 & -0.90 & 0.60 & 0.44 & 7.78 & 0.75 & 1.27 & 0.49 \\
\hline Brother \#5 & III & 35 & Yes & Yes & No & No & 42.5 & 44.4 & -1.90 & 0.59 & 0.47 & 8.01 & 2.65 & 3.98 & 0.96 \\
\hline Brother\#5 & III & 35 & Yes & Yes & Yes & No & 42.5 & 44.4 & -1.90 & 0.62 & 0.48 & 8.04 & 2.67 & 4.19 & 0.93 \\
\hline Mother & I & 58 & No & No & No & No & 43.9 & 44 & -0.10 & 0.08 & 0.26 & 7.73 & 0.89 & 0.94 & 0.4 \\
\hline Mother & I & 58 & No & No & No & No & 43.3 & 44 & -0.70 & 0.26 & 0.32 & 7.76 & 1.15 & 1.1 & 0.42 \\
\hline Father & I & 62 & No & No & No & No & 43.8 & 43.9 & -0.10 & 0.56 & 0.43 & 7.80 & 0.11 & 0.36 & 0.35 \\
\hline Father & 1 & 62 & No & No & No & No & 43.8 & 44.3 & -0.50 & 0.58 & 0.20 & 7.78 & -0.34 & 0.38 & 0.53 \\
\hline \multicolumn{7}{|c|}{ Average patients } & 43.21 & 44.53 & -1.31 & 0.55 & 0.43 & 7.77 & 1.08 & 1.77 & 0.60 \\
\hline \multicolumn{7}{|c|}{ Average patients (without father and sister \#3) } & 43.19 & 44.80 & -1.61 & 0.55 & 0.48 & 7.74 & 1.45 & 2.28 & 0.67 \\
\hline
\end{tabular}

Grade*: Keratoconus severity score (after McMahon et al) ${ }^{13}$; K: Simulated keratometric reading; BFS: Best fit sphere; I-S: Inferiorsuperior difference; SAI: Surface asymmetry index; SRI: Surface regularity index; E: Corneal eccentricity 

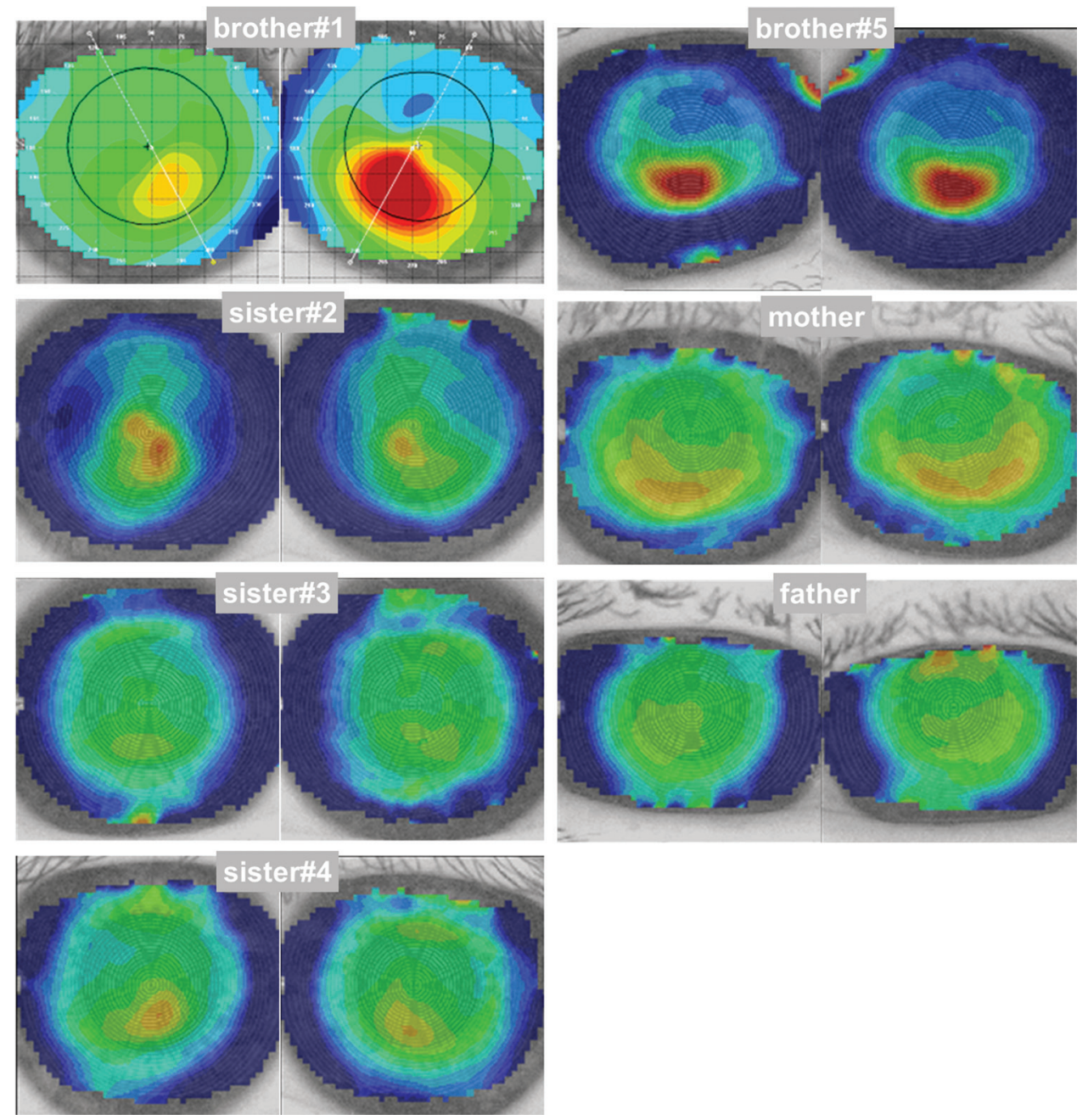

Fig. 2: Pairs of tangential topographical maps (right eye to the left of each pair) for the family members screened. Pairs of right and left eye, from top to bottom: brother \#1 (33 yrs); sister \#2 (26 yrs); sister \#3 (26 yrs); sister \#4 (28 yrs); brother \#5 (35 yrs); mother (58 yrs) and father (62 years). All images correspond with the tangential map and absolute scale (37D for dark blue, 49D for red)

a preliminary examination, she achieved UCVA 20/15 with her RE and 20/15- with LE. Refractive examination showed irregular retinoscopic reflex in LE and subjective refraction was (RE plano 20/15 and LE $-2.25 \times 125$ 20/40) and no clear end-point in LE. Topographic examination demonstrated a typical asymmetric pattern in LE and asymmetry between both corneas as shown in Figure 2subject 4 . Other topographic details and biomicroscopic signs are reported in Table 1.

By March 2009, brother \#5 (35 years old) was screened as well as their father and mother. Again despite all of them reported no complains of poor or worsening vision compatible with keratoconus, brother \#5 showed quite distorted retinoscopy reflexes in both eyes under dim room conditions. Topography showed accentuated pattern of localized paracentral inferior steepening compatible with keratoconus in both corneas (Fig. 2-subject 5). UCVA was RE 20/15- and LE 20/30-. Refractive error was RE plano 20/15- and LE -2.25 × 125 20/30. Patient's relatively good vision at distance could in part be due to his light blue eyes and pupil constriction. Surprisingly, the patient did not reported expontaneously complains of vision despite being a bus driver. He only reported photofobia and certain eye burning in sunny days, what he attributed to the color of his eyes.

The father (62 years old) presented with unremarkable ocular history and distance vision correction was plano in both eyes. Incipient cataract formation was noted in both eyes, with remaining biomicroscopic examination being unremarkable. Topographic and biomicroscopic findings were unremarkable except for a slightly decentered steepest anterior topography in both eyes. The mother reported history of central vein occlusion in LE with a certain degree of vision loss. However, corneal topography showed a somewhat smile-like pattern in both eyes (Fig. 2-subject 7). Again all quantitative parameters are displayed in Table 1.

\section{DISCUSSION}

The present case series shows a singular presentation pattern of familial keratoconus. To the best of our knowledge, this is the first report presenting five siblings, with 
signs of keratoconus or the diagnostic being confirmed. Several literature reports have clearly shown familial associations in as high as $23.5 \%$ of the patients identified in a cohort of New Zealanders. ${ }^{18}$ In the US, the CLEK study baseline data has reported a $13.5 \%$ of cases with known affected members. ${ }^{10}$ In the same group, SzcotzkaFlynn et al concluded that presence or absence of family history is not associated with more severe clinical disease, however they found Caucasian ethnic group along with other risk factors could display higher prevalence of keraotconus in patient's family members. ${ }^{19}$ In a study, conducted in Iran 300 eyes from 150 relatives of 45 patients with keratoconus. Of them, keratoconus was diagnosed in $14 \%$ and another $7.3 \%$ were considered suspicious of keratoconus. ${ }^{20}$ Present report also reinforces the recommendations of those studies in the sense of being particularly aware of potential presentation of keratoconus in direct relatives of diagnosed patients.

Another related issue that has been subject of interest in past years has been the potential higher prevalence of keratoconus in monozygotic twins as compared with dizygotic twins. This approaches tried to demonstrate the genetic involvement in keratoconus and despite some reports disagree, most of the results published in the review of literature conducted by Rabinowitz supported the genetic association in keratoconus found more familial associated cases in brothers or sisters in monozygotic twins compared to dizygotic twins. ${ }^{21}$ In the present case series, despite keratoconus could not be confirmed in one of the sisters, the topographical pattern, particularly when compared with the remaining elements in Figure 3, and topographic indices suggests that some degree of distortion is also present, thus, warranting a closer follow-up.

Of relevance is also the relatively similar pattern of deviation of the apex in the inferior or inferonasal quadrant which was common to most of the elements in this series (Fig. 3). This is quite surprising due to the known wide range of topographical patterns adopted by the disease. ${ }^{21}$ In the case of the sister where the disease was not confirmed, the inferior steepening is also present with values of inferior-superior difference higher than average values found in nonaffected controls using the
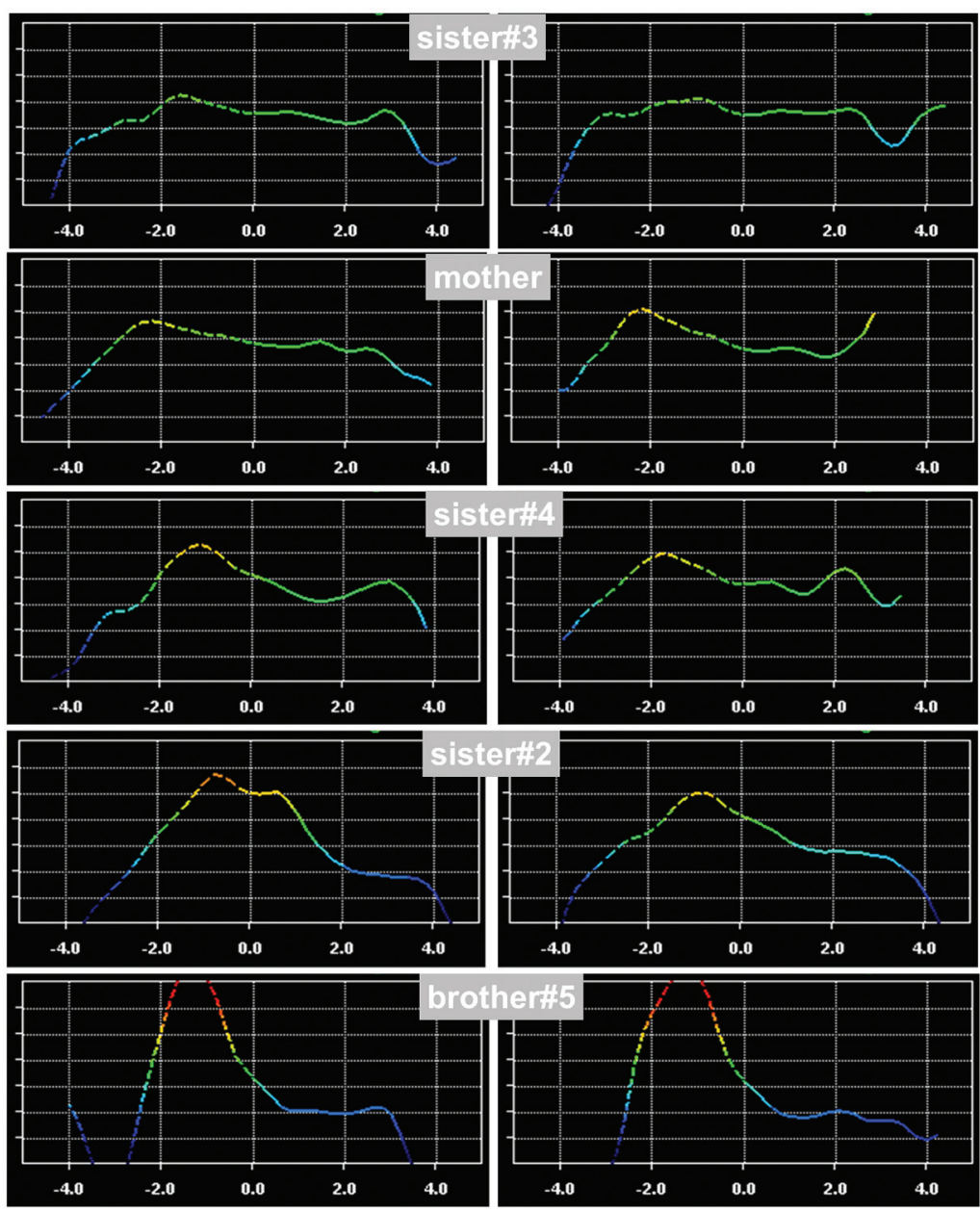

Fig. 3: Pairs of topographical profiles across the steepest meridian in the tangential absolute map (right eye to the left of each pair) for the series of members with a consistent profile of apex location and curvature progression towards periphery. From top to bottom: sister \#3; mother \#6; sister \#4; sister \#2; brother \#5. All cross-sections correspond to the steepest meridian of the tangential map in absolute scale (36.4D for dark blue, 49.6D for red) 
same topographer (unpublished data). Despite diagnosis of keratoconus was not confirmed, and despite having good distance visual acuity, except in one eye due to a past episode of central vein occlusion, the mother showed atypical topographies (smile shape) in both eyes. Similar topographical patterns in members of the same family of patients with keratoconus were reported by Levy et al. ${ }^{16}$ It's also of relevance that the more advanced cases were found in the two brothers; however, being the older ones, age could also play a role on this regard. The qualitatively and quantitative almost symmetrical presentation of the disease in both corneas of brother \#5 is also remarkable.

According with the different degrees of evolution, different clinical signs were observed, with particular attention for visibility of corneal nerves even in the paracentral and central area and Fleischer's ring. Both signs have been extensively reported in the literature and their concurrence in keratoconic eyes is well documented. ${ }^{2}$ Other relevant issue in keratoconus and visual acuity is the stronger decrease in low-contrast visual acuity even when high-contrast VA can remain at normal levels. This pattern of stronger visual loss under low-contrast conditions is supported by the long-term visual impact of keratoconus in the CLEK Study. ${ }^{22}$ Although low-contrast VA was not tested for all subjects, those being tested performed significantly worse and some of those being asked for their visual skills when viewing low contrast text (newspaper, phone directories, foggy/rainy daytime viewing,...) agreed they were somewhat challenged under these conditions.

A closer analysis of the topographic data (simulated keratometry and eccentricity) showed they were not much different from those presented in normal population. This is due in part to the limited extension of the cone and the mostly central location, thus affecting poorly the simulated keratometric calculations and more peripheral reference points for eccentricity calculations. However, indices of asymmetry (SAI and I-S) and irregularity (SRI) are altered compared to those of the normal population that served as comparison.

In conclusion, the present report highlights the importance of history taking in patients with keratoconus and the need to screen other members of the family when one case is detected. The variety of presentations also concern to the concurrence of several clinical signs in addition to topographic characteristic patterns. Some patients might nor report poor vision, and detailed attention should be paid to corneal topopraphic indices and patterns under different map viewing options and with different scales to catch potential abnormal or slightly abnormal data in an apparently normal eye at a first glance. All these conclusions have to be in mind of refractive corneal surgeons because of the potential implications for these procedures.

\section{REFERENCES}

1. Romero-Jimenez M, Santodomingo-Rubido J, Wolffsohn JS. Keratoconus: a review. Cont Lens Anterior Eye 2010;33: 157-166.

2. Zadnik K, Barr JT, Gordon MO, Edrington TB. Biomicroscopic signs and disease severity in keratoconus. Collaborative Longitudinal Evaluation of Keratoconus (CLEK) Study Group. Cornea 1996;15:139-146.

3. Mannis MJ, Zadnik K. Contact lens fitting in keratoconus. CLAO J 1989;15:282-289.

4. Lembach R. Use of contact lenses for management of keratoconus. Ophthalmol Clin North Am 2003;16:383-394.

5. Betts AM, Mitchell GL, Zadnik K. Visual performance and comfort with the Rose K lens for keratoconus. Optom Vis Sci 2002;79:493-501.

6. Edrington TB, Szczotka LB, Barr JT, et al. Rigid contact lens fitting relationships in keratoconus. Collaborative Longitudinal Evaluation of Keratoconus (CLEK) Study Group. Optom Vis Sci 1999;76:692-699.

7. González-Méijome JM, Peixoto-de-Matos SC, Queiros A, et al. Quality of vision with spectacles, special silicone hydrogel and gas permeable contact lenses in keratoconic patients. Int J Kerat Ect Cor Dis 2013;2:56-59.

8. Lopez-Alemany A, Gonzalez-Meijome JM, Almeida JB, et al. Oxygen transmissibility of piggyback systems with conventional soft and silicone hydrogel contact lenses. Cornea 2006;25:214-219.

9. Gonzalez-Meijome JM, Jorge J, de Almeida JB, Parafita MA. Soft contact lenses for keratoconus: Case report. Eye Contact Lens 2006;32:143-147.

10. Zadnik K, Barr JT, Edrington TB, et al. Baseline findings in the Collaborative Longitudinal Evaluation of Keratoconus (CLEK) Study. Invest Ophthalmol Vis Sci 1998;39:2537-2546.

11. Edwards M, McGhee CN, Dean S. The genetics of keratoconus. Clin Experiment Ophthalmol 2001;29:345-351.

12. Burdon KP, Coster DJ, Charlesworth JC, et al. Apparent autosomal dominant keratoconus in a large Australian pedigree accounted for by digenic inheritance of two novel loci. Hum Genet 2008;124:379-386.

13. Gajecka M, Radhakrishna U, Winters D, et al. Localization of a gene for keratoconus to a 5.6-Mb interval on 13q32. Invest Ophthalmol Vis Sci 2009;50:1531-1539.

14. Udar N, Atilano SR, Brown DJ, et al. SOD1: a candidate gene for keratoconus. Invest Ophthalmol Vis Sci 2006;47:3345-3351.

15. Tyynismaa H, Sistonen P, Tuupanen S, et al. A locus for autosomal dominant keratoconus: linkage to $16 \mathrm{q} 22.3-\mathrm{q} 23.1$ in Finnish families. Invest Ophthalmol Vis Sci 2002;43:3160-3164.

16. Levy D, Hutchings $H$, Rouland JF, et al. Videokeratographic anomalies in familial keratoconus. Ophthalmology 2004; 111:867-874.

17. McMahon TT, Szczotka-Flynn L, Barr JT, et al. A New Method for Grading the Severity of Keratoconus: The Keratoconus Severity Score (KSS). Cornea 2006;25:794-800.

18. Owens H, Gamble G. A profile of keratoconus in New Zealand. Cornea 2003;22:122-125.

19. Szczotka-Flynn L, Slaughter M, McMahon T, et al. Disease severity and family history in keratoconus. Br J Ophthalmol 2008;92:1108-1111.

20. Karimian F, Aramesh S, Rabei HM, et al. Topographic evaluation of relatives of patients with keratoconus. Cornea 2008;27:874-878.

21. Rabinowitz YS. The genetics of keratoconus. Ophthalmol Clin North Am 2003;16:607-620.

22. Davis LJ, Schechtman KB, Wilson BS, et al. Longitudinal changes in visual acuity in keratoconus. Invest Ophthalmol Vis Sci 2006;47:489-500. 